\title{
Self-potential anomaly of Satsuma-Iwojima volcano
}

\author{
Wataru Kanda and Sin'yo Mori \\ Sakurajima Volcano Research Center, Disaster Prevention Research Institute, Kyoto University, Sakurajima, Kagoshima 891-1419, Japan
}

(Received April 28, 2000; Revised December 25, 2000; Accepted Feburary 14, 2001)

\begin{abstract}
We conducted self-potential (SP) surveys twice at Satsuma-Iwojima volcano where an intense fumarolic activity continued for more than 1000 years from a summit crater of Iwodake, a lava dome of rhyolite. A positive anomaly of $200 \sim 250 \mathrm{mV}$ was detected on the Iwodake edifice, although the survey area was limited because of the steep topography and existence of high temperature fumaroles. The anomaly seems to be centered at the summit crater of Iwodake and can roughly be explained by a pair of conduction current source and sink located around the sea level beneath the summit crater. Depth of the current source might indicate the upper end of a liquid-phase water upflow zone, where the liquid-phase water vaporizes due to heat and depressurization. The above model does not explain the additional positive SP anomaly around the summit crater and on the western flank. The anomaly around the summit might be caused by suppression of meteoric water downflow by high temperature volcanic gases. The positive anomaly on the western flank might be caused by local fluid upflows associated with fumaroles on the flank.
\end{abstract}

\section{Introduction}

Satsuma-Iwojima is a volcanic island located on northwestern margin of the Kikai Caldera that was formed by eruptive activities about 6,300 years ago (Fig. 1). Eruptions were not recorded in the historic age except that a new rhyolitic island was created by a submarine eruption at $3 \mathrm{~km}$ east of Satsuma-Iwojima in 1934. However, an intense fumarolic activity has been known for at least 1000 years from the summit crater and flank of Iwodake, a post-caldera dome of rhyolite, located at the eastern half of the island (Yoshida and Ozawa, 1981). Detailed geology and chronology of Satsuma-Iwojima is summarized by Ono et al. (1982). Recently, earthquake swarms occurred in April 1998 and high seismicity lasted for about a year with occasional ash ejections. The O-hachi fumarolic vent was recognized inside the summit crater in 1991 and has been gradually expanding since then (Geological Survey of Japan, 1997).

Self-potential (SP) surveys have been conducted in many volcanoes of subduction zones (e.g., Nishida and Tomiya, 1987; Sasai et al., 1997; Di Maio et al., 1998) as well as of hotspots (e.g., Zablocki, 1976; Michel and Zlotnicki, 1998). A positive sense anomaly of about a few hundreds to more than a thousand millivolts was detected on most of those volcanoes. Electrokinetic effect associated with subsurface fluid upflows is considered to be the most probable cause of such a large anomaly, so that the SP data is often used as an indicator of the hydrothermal activity of volcanoes. In order to get better understanding of volcanic activities, our group has conducted the SP surveys at active volcanoes in subduction zone of South Kyushu region (Sakurajima volcano by Hashimoto et al., 1998, 1999; Suwanosejima volcano by

Copy right (C) The Society of Geomagnetism and Earth, Planetary and Space Sciences (SGEPSS); The Seismological Society of Japan; The Volcanological Society of Japan; The Geodetic Society of Japan; The Japanese Society for Planetary Sciences.
Kanda et al., 1999). Recently, volcanic fluid such as water or gases at shallow part is considered to play an important roll as a factor of controlling the eruption type (e.g., Kagiyama et al., 1999). If the observed positive SP anomaly is related to the subsurface hydrothermal activity, we expect to find some relationship between amplitude or spatial dimension of the SP anomaly and degree of the volcanic activity.

Objective of this study is to reveal the hydrothermal system beneath the Satsuma-Iwojima volcano from the SP surveys. A large-scale positive anomaly is expected around the summit crater since a rhyolitic magma has been staying at the shallow depth without eruption for more than 1,000 years (e.g., Kazahaya and Shinohara, 1996). Although a SP mapping on the island was carried out in 1977, presence of the large-scale positive anomaly was not obvious in the result due to insufficient data points around the summit crater (unpublished report).

\section{Measurements}

We conducted the SP surveys on Satsuma-Iwojima volcano in July and November 1999. The surveys were focused on SP distribution of the Iwodake edifice, however the surveyed area was limited by the steep topography and distribution of stiff rhyolitic lavas as shown in Fig. 1. During the first survey of July, SP was measured along the traverse to the summit crater from the southwestern coast of Iwodake close to Higashi hot spring. Acid gas environment and distribution of high temperature fumaroles $\left(>800^{\circ} \mathrm{C}\right)$ in the crater did not allow us to extend the survey area into the summit crater. The second survey was conducted in November in order to obtain the SP profile over the island. The survey area was extended to Ohura coast (western edge of the island), to Sakamoto hot spring (northwestern edge), and to the western flank and the northern foot of Iwodake.

Measuring method was as follows. We used a pair of 


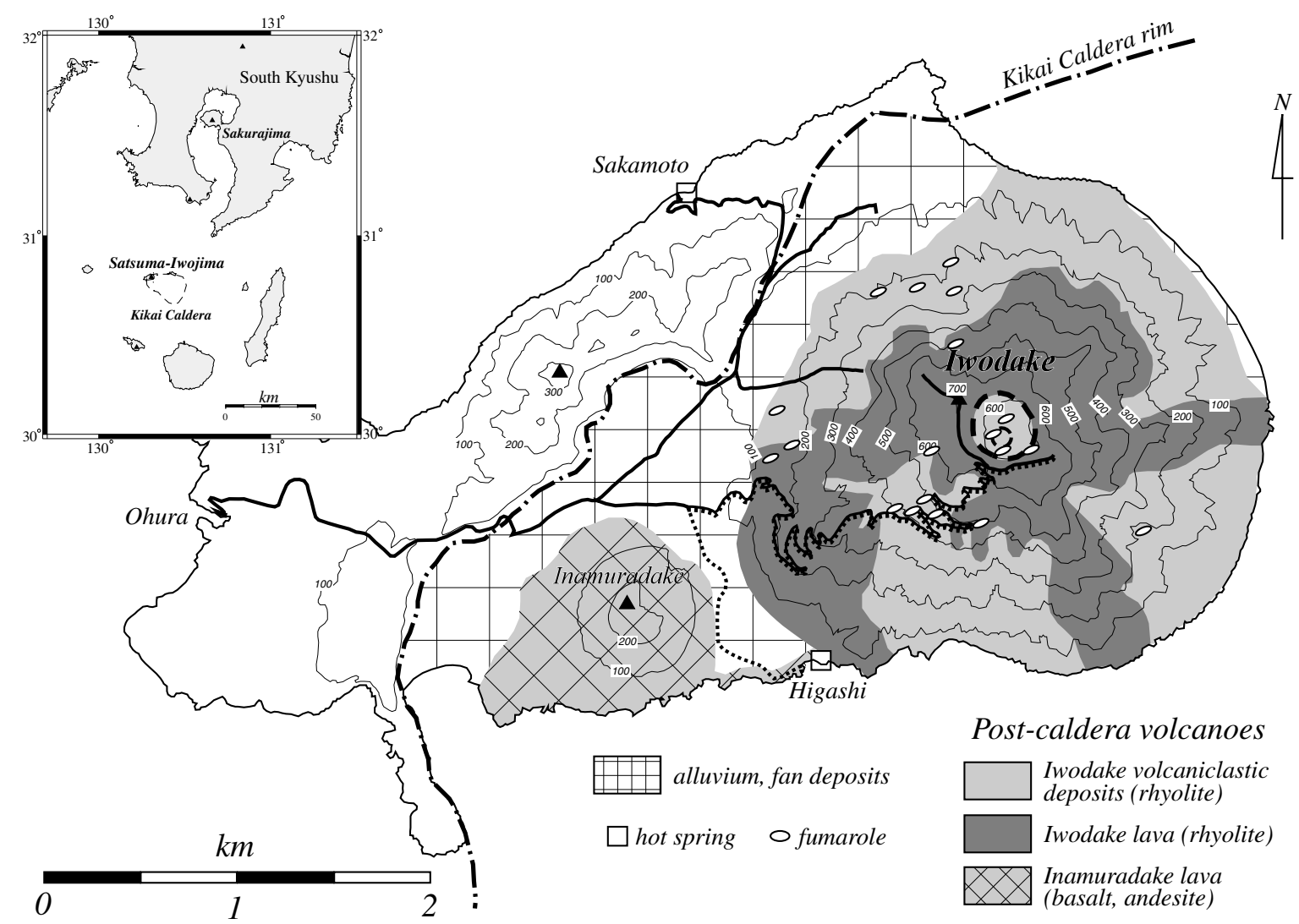

Fig. 1. Location map of Satsuma-Iwojima volcano. The SP measurements were made along the thick solid lines (November 1999) and along the dotted lines (July 1999). Simplified geology inside the caldera is taken from Ono et al. (1982). Outer part of the caldera consists of the andesitic to rhyolitic lavas of the pre-caldera volcanoes.

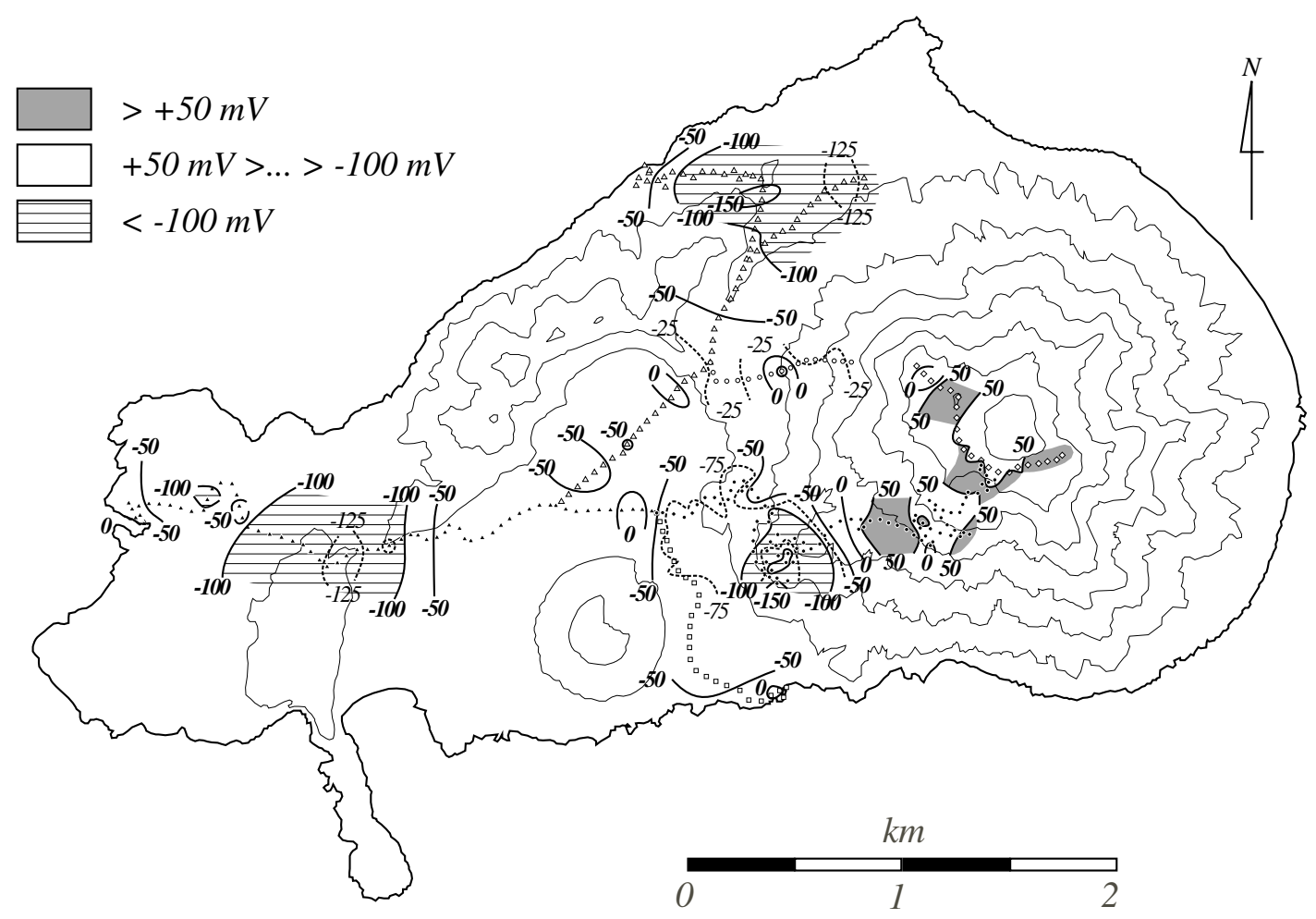

Fig. 2. Results of the SP surveys conducted in 1999. The data are given as the relative values to potential of the seawater at the Ohura coast, western edge of the island. Symbols (circles, triangles, diamonds, and squares) show the measurement points which correspond to those shown in Figs. 3 and 4 . The data points along the traverse of the Iwodake edifice in July 1999 (open squares) are not shown because of overlap with those in November. 
non-polarizing electrodes and a cable with $400 \mathrm{~m}$ long. A lead-lead chloride electrode was buried at $5 \sim 10 \mathrm{~cm}$ depth as a reference and the other electrode, which was either of a lead-lead chloride or a copper-copper sulfate, was moved along the survey path with measuring potential differences every $50 \mathrm{~m}$ from 0 to $400 \mathrm{~m}$ by using a high impedance voltmeter. When a copper-copper sulfate was used as the travelling electrode, potential of about $500 \mathrm{mV}$ was superimposed on the voltages. This inflated voltage has an advantage to distinguish the SP variation from the fluctuation caused by troubles during the measurement such as snapping of a cable or change in grounding condition of the reference electrode (Hashimoto et al., 1998). Electromagnetic noise level was very low over the island, so that no filters were used for the data acquisition. Voltages were measured $3 \sim 4$ times with moving the electrode about $10 \mathrm{~cm}$ at each site and the average was used to avoid extremely local anomalies. Deviation from the averaged value was less than $10 \mathrm{mV}$ in most sites, however the electrochemical effect of about a few to $10 \mathrm{mV}$ (e.g., Nourbehecht, 1963; Corwin and Hoover, 1979) might contaminate the data at some sites. The reference electrode was picked up every $400 \mathrm{~m}$ and the cycle of measurement was repeated to the end points.

Ground temperature was also measured at all measurement sites during the second survey, since geothermal features such as fumaroles and steaming ground were seen at some points on Iwodake during the first survey. The DATAMARK LS3300ptV system (Hakusan Co., Tokyo), which consists of the 16-bit data logger and the platinum sensor, was used for the measurement. The measurement was made at $20 \mathrm{~cm}$ depth and in a few minutes.

\section{SP Anomaly}

The SP distribution of Satsuma-Iwojima volcano are shown in Fig. 2. SP data of the two surveys were compiled and represented as the relative values to the potential of the seawater at Ohura coast. The potentials ranging from -200 to $+100 \mathrm{mV}$ are observed. The potentials lower than -100 $\mathrm{mV}$ are distributed along the rim of the Kikai Caldera and at southwestern flank of Iwodake, at an altitude of 200 to 300 m. Values higher than $+50 \mathrm{mV}$ are only observed around the summit crater and at southern flank of Iwodake. The potentials on the alluvium ground (see Fig. 1) are ranging from -50 to $0 \mathrm{mV}$.

Some features are found in the relationship between altitude and the SP data measured in November 1999 (Fig. 3). The potential along the survey paths on the alluvium ground to the outer part of the caldera (solid triangles and a part of open triangles) shows the negative correlation with altitude of $-2 \sim-3 \mathrm{mV} / \mathrm{m}$. Although some data shown by open triangles does not follow the same trend, those sites are located along the saddle between the caldera rim and Iwodake. Negative correlation with topography is also recognized along the traverse to the summit crater of Iwodake (solid circles) at altitudes from 100 to $300 \mathrm{~m}$ above sea level, although its slope is smaller $(-0.5 \sim-1 \mathrm{mV} / \mathrm{m})$.

The potential increases by about $200 \mathrm{mV}$ at altitudes from 300 to $400 \mathrm{~m}$ along the traverse to Iwodake approaching to the summit. The high SP values are nearly constant at altitudes from 400 to $600 \mathrm{~m}$ (solid circles) and around the

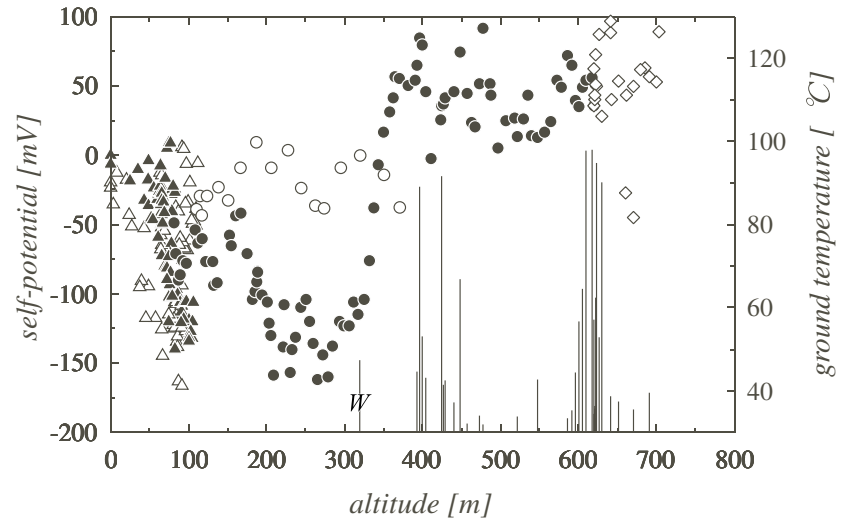

Fig. 3. The SP data plotted against altitude of the measurement point. The data obtained in November 1999 are shown. Bar graph shows the $20 \mathrm{~cm}$ depth ground temperature. Only one value noted with "W" is the data from the western flank and the rests are the data from the southern flank. Each symbol corresponds to the survey path shown by the same symbol in Fig. 2.

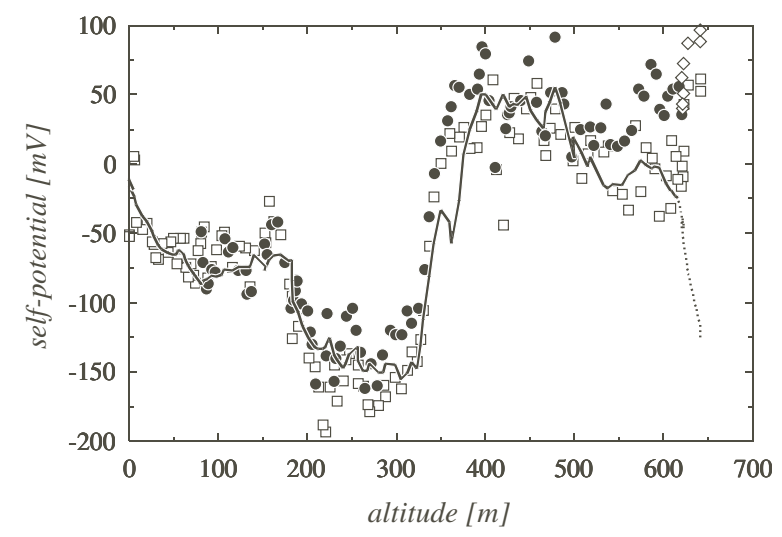

Fig. 4. The best-fit model for $Z_{s}=-100$ (solid line) shown in Table 1 and the data observed in July 1999 (open squares). The data along the same traverse obtained in November (solid circles and open diamonds) are also shown. The dotted line shows the extrapolated data around the summit crater from the model.

summit crater (open diamonds). Referring to the lowest SP around $300 \mathrm{~m}$ in elevation, the amplitude of a positive anomaly seen over the southwestern part of the Iwodake edifice is about $200 \sim 250 \mathrm{mV}$. The same tendency was observed during the first survey in July 1999 (Fig. 4).

The correlation with topography is not obvious along the survey path on the western flank of Iwodake (open circles). The potentials range from -50 to $0 \mathrm{mV}$, which are higher than those of the measurements at the same altitude of the southwestern traverse (solid circles). A small area of positive anomaly can be recognized on the western flank (Fig. 2).

The $20 \mathrm{~cm}$ depth ground temperatures higher than $30^{\circ} \mathrm{C}$ are shown in Fig. 3. No corrections were made on this data for probable effects of diurnal variation of atmospheric temperature (roughly $15 \sim 25^{\circ} \mathrm{C}$ during the observation) and its altitude dependence (generally $-0.005 \sim-0.006^{\circ} \mathrm{C} / \mathrm{m}$ ).

The high temperature areas $\left(>40^{\circ} \mathrm{C}\right)$ are only observed on the Iwodake, where the high SP is observed. Ground temperature higher than $80^{\circ} \mathrm{C}$ is observed around the summit 


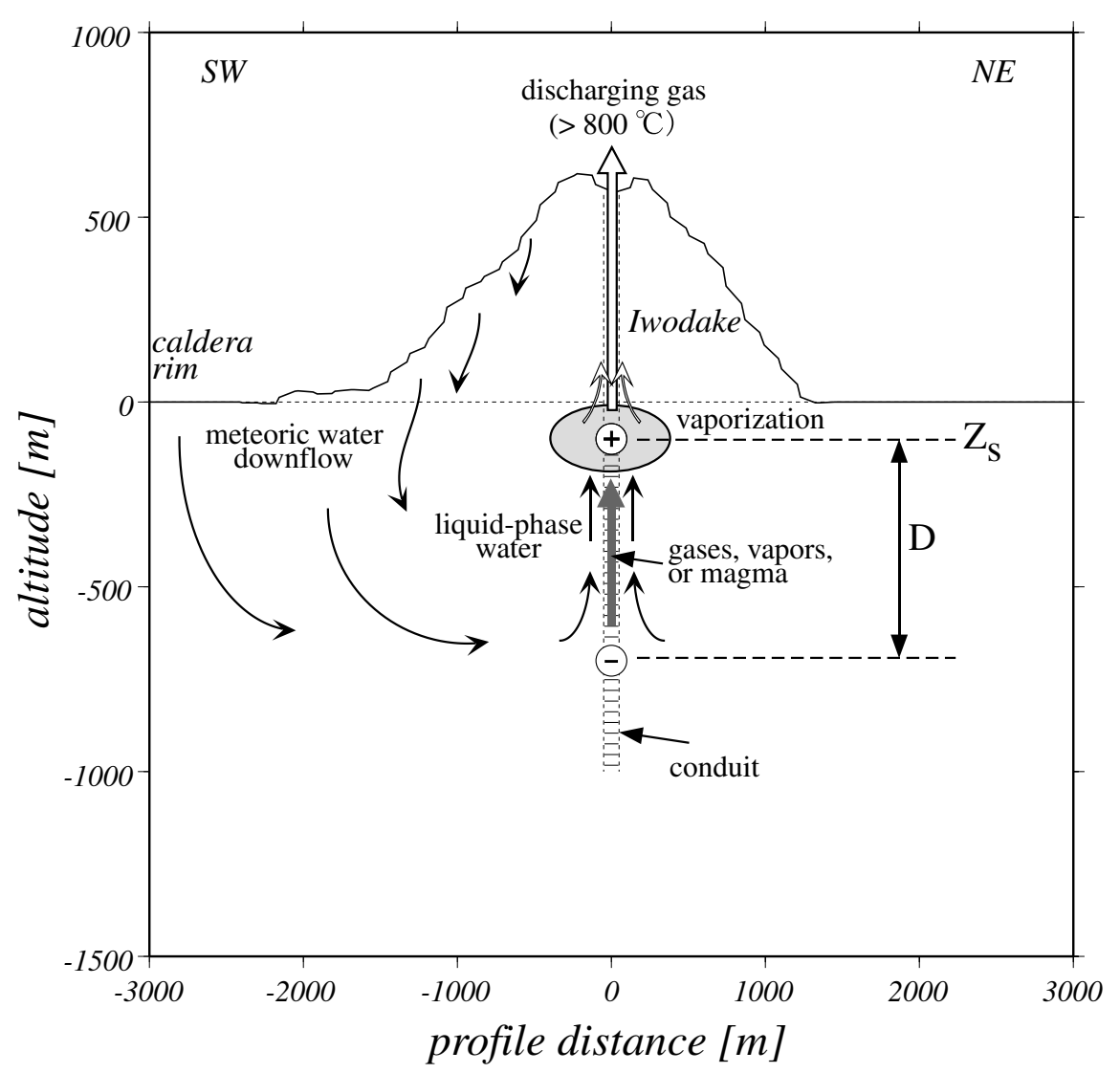

Fig. 5. Schematic model of the hydrothermal system beneath Satsuma-Iwojima volcano (SW-NE section). A circle with plus and that with minus represent locations of conduction current source and sink, respectively.

crater rim close to the active vent and at altitudes of 400 to $450 \mathrm{~m}$. High SP values are also measured around these two areas. Both the ground temperature and the SP are somewhat depressed at the altitude between 450 and $600 \mathrm{~m}$.

High temperature of $47^{\circ} \mathrm{C}$ is observed at an altitude of $320 \mathrm{~m}$ on the western flank. Relatively high SP is observed at this high temperature point which is located at just north of the fumarolic area (Fig. 1). The positive SP anomaly over the western flank might reflect the local thermal feature.

\section{A Model for the Positive SP Anomaly}

As described in the previous section, the positive anomaly at the center and the negative correlation with topography at outlier area were found along the traverse of the Iwodake edifice. The SP profile shown in Fig. 3 was similar to those found in many other volcanoes. Zlotnicki et al. (1998) illustrated this typical SP pattern as follows. The electrokinetic effect of the subsurface fluid upflow and the thermoelectric effect of the heat source are superimposed upon the largescale topographic effect caused by the infiltrating meteoric water. However, contribution of the thermoelectric effect is considered to be small compared to that of the electrokinetic effect (Corwin and Hoover, 1979). Based on this interpretation, we tried to fit the observed SP profile of Iwodake to a simple model as follows.

The positive anomaly was modeled by a pair of point source and sink of electric conduction current which were assumed to be located just beneath the active O-hachi fu- marolic vent in the summit crater at different depth. Since it is difficult to separate contributions from the electrokinetic and the thermoelectric effects, both contributions to the potential are represented by an inverse function of the distance (Patella, 1997). Topographic effect was taken into account as a linear function (Ishido, 1989). Therefore, the potential $(f)$ is given as a function of position of the measurement point: horizontal distance from the vent $r$ and altitude $z$,

$$
f(r, z)=A \cdot\left(\frac{1}{R_{1}}-\frac{1}{R_{2}}\right)-B \cdot z+C
$$

$$
R_{1}=\sqrt{r^{2}+\left(z-Z_{s}\right)^{2}} \quad R_{2}=\sqrt{r^{2}+\left(z-\left(Z_{s}-D\right)\right)^{2}}
$$

where $R_{1}$ and $R_{2}$ denote the distances to the measurement point from the source and from the sink, respectively. $Z_{s}$ is altitude of the current source above sea level and $D$ is the vertical distance between the source and sink (Fig. 5). Unknown parameters of $A, B, C, D$, and $Z_{s}$ are determined by a grid-search technique so as to minimize the misfit defined as

$$
\gamma=\sqrt{\frac{1}{N} \sum^{N}(\operatorname{SP}(r, z)-f(r, z))^{2}}
$$

where $N$ denotes number of the data to be fitted $(\operatorname{SP}(r, z))$. The observed SP profile of July 1999 was used as $\operatorname{SP}(r, z)$, because the profile of the single path covers from the summit to sea level on the foot of Iwodake (Fig. 1). 
Table 1. Best-fit models in the searched parameter space.

\begin{tabular}{lccccccc}
\hline parameter & search range & increment & \multicolumn{5}{c}{ best-fit models } \\
\hline$Z_{s}[\mathrm{~m}]$ & $-1500 \sim 500$ & 50 & 0 & -50 & -100 & -150 & -200 \\
$A[\mathrm{mV} \cdot \mathrm{km}]$ & $100 \sim 3000$ & 10 & 640 & 780 & 970 & 1350 & 2000 \\
$B[\mathrm{mV} / \mathrm{m}]$ & $0.50 \sim 1.50$ & 0.05 & 0.95 & 0.85 & 0.90 & 0.90 & 0.85 \\
$C[\mathrm{mV}]$ & $-200 \sim 100$ & 10 & -100 & -80 & -70 & -60 & -60 \\
$D[\mathrm{~m}]$ & $50 \sim 2000$ & 50 & 1200 & 850 & 600 & 400 & 250 \\
\hline
\end{tabular}

A number of models reasonably satisfied the data at equivalent misfit level $(\gamma<25.00)$. The source location depth $\left(Z_{s}\right)$ of the best-fit models was relatively well restricted in the range from 0 to $-200 \mathrm{~m}$. The parameters of best-fit model for each $Z_{s}$, every $50 \mathrm{~m}$ from 0 to $-200 \mathrm{~m}$, are listed in Table 1 and the curve of $f(r, z)$ for the model of $Z_{s}=-100 \mathrm{~m}(\gamma=24.70)$ is shown in Fig. 4 as well as the observed results. When the smaller $Z_{s}$ was selected, combination of a large $D$ and a small $A$ values were obtained (Table 1). The best-fit model reproduces the observed SP pattern well except near the summit crater.

The disagreement near the summit area indicates that the linear topographic effect does not hold there. The linear correlation is based on assumptions that the water table is shallow and closely follows the ground surface and that physical parameters of rocks (i.e., permeability, resistivity, etc.) are homogeneous (Ishido, 1989). Ishido et al. (1997) showed by a numerical simulation that relatively high SP appeared around the summit on a volcano with a deeper water table beneath the summit area than beneath the flank. The assumption of the linear topographic effect will not be valid if meteoric water downflows at the summit area are suppressed by intense upflows of high temperature volcanic gases as also shown by Ishido et al. (1997).

The data observed along the western flank of Iwodake does not agree with the above model. This possibly implies that the parameter $B$ related to the topographic effect at the western flank is smaller than the estimated $B$ value using the data along the southwestern part of Iwodake. According to the simulation results shown by Yasukawa and Mogi (1998), a smaller $B$ value is expected when permeability or resistivity beneath the area is smaller.

The parameter $A$ is proportional to the product of resistivity of the medium and conduction current strength. Current strength is calculated as $1 \sim 3 \mathrm{~A}$ when we adopt 10 $\Omega \mathrm{m}$ as an average resistivity of the Iwodake edifice. However, the parameter $A$ was searched together with $B$ under the assumption that the linear topographic effect holds even around the summit area, so that the $A$ parameter and the consequent current strength would be overestimated.

\section{Discussion}

Ishido et al. (1997) performed numerical simulations of the hydrothermal convection before and after a magma intrusion into shallow part of a volcano to interpret the stable positive sense SP anomaly centered over the active vent of Izu-Oshima volcano, Japan. Based on their results, ascent of high temperature volcanic gases above the magma sup- pressed meteoric water downflows and resulted in the relatively high potential around the summit crater. Their simulation also showed that an upward liquid-phase flow was evolved around the intruded magma and produced a source of the positive sense SP, although they concluded that contribution of the upward liquid-phase flow to the observed SP was minor due to its deep location.

However, under certain conditions of a magma-hydrothermal system such as that with a shallow magma head, the positive SP caused by the liquid-phase upflow would be significant. This is probably the case in Satsuma-Iwojima volcano since the observed SP around the summit area is higher than zero (50 $\sim 100 \mathrm{mV}$ as shown in Fig. 3) referring to the potential of the seawater of the western coast about $5 \mathrm{~km}$ away from the summit. The SP with positive polarity around the summit cannot be explained even if the meteoric water downflow is completely suppressed.

High temperature fumarolic gases with high $\mathrm{H}_{2} \mathrm{O}$ content have been discharged from active vents in the summit crater of the Iwodake (Shinohara et al., 1993). On the basis of geochemical data, Kazahaya and Shinohara (1996) proposed that the degassing magma located at a shallow part. This hypothesis was supported by melt inclusion study which can estimate the degassed pressure from the magma (Saito et al., 1996). Volcanic earthquakes with volume expanding mechanism also suggested existence of flows of gas or liquid phase at the shallow part beneath the active vent (Ohminato and Ereditato, 1997; Iguchi et al., 1999).

Depth of the conduction current source $\left(Z_{s}\right)$ was estimated to be ranging from zero to two hundreds meters below the sea level (Table 1). Liquid-phase water flow driven by heat of the intruded magma or of the vapor-phase upflow above the degassing magma would carry positive charge to location of the conduction current source (Fig. 5). At depth of the source, the liquid-phase water vaporizes due to the heat and depressurization. Since the vaporized water is no longer a carrier of the charge, the positive charge is accumulated at that depth, creating a source of conduction current (Fig. 5).

If the conduction current is equivalent to drag current associated with the liquid-phase water upflow, we can estimate the flow flux with some assumptions (e.g., Ishido, 1991). When the capillary model (Ishido and Mizutani, 1981) for a porous medium is considered, electric current strength $I$ generated by the electrokinetic coupling of a fluid flow with volumetric flux of $J$ is expressed as:

$$
I=\frac{\eta t^{-2} \epsilon|\zeta|}{\kappa} J
$$


where $\eta, t$, and $\kappa$ denote porosity, tortuosity, and permeability of the porous medium, respectively. We take $\eta t^{-2}=0.1$ as a representative value of the crust. $\kappa$ is treated as an unknown parameter because rock permeability is highly variable ranging over several orders of magnitude and no in-situ value is available at Satsuma-Iwojima. $\epsilon$ is dielectric constant of the pore fluid and is $3.1 \times 10^{-10} \mathrm{~F} / \mathrm{m}$ for water at $200^{\circ} \mathrm{C}$ under saturation condition (Helgeson and Kirkham, 1974). If temperature is higher than $200^{\circ} \mathrm{C}$, a smaller value is expected but it is the same order $\left(\sim 1 \times 10^{-10}\right)$. $\zeta$ denotes the zeta potential, that is electric potential across the electrical double layer. It is known that the zeta potential depends on $\mathrm{pH}$ as well as temperature and electrolyte concentration of the aqueous solution (e.g., Ishido and Mizutani, 1981). Ishido et al. (1983) evaluated that electrolyte concentration of the solution causes little change in the zeta potential under high temperature condition $\left(>150^{\circ} \mathrm{C}\right)$ and estimated the zeta potential at $200^{\circ} \mathrm{C}(\mathrm{pH} \sim 8)$ to be $-0.1 \mathrm{~V}$. We adopt this value. Taking the density of saturated water at $200^{\circ} \mathrm{C}$ $\left(=0.87 \mathrm{ton} / \mathrm{m}^{3}\right)$ into account, the flow flux $J$ is estimated as $2 \sim 7 \times 10^{16} \kappa$ ton/day to cause $I$ of $1 \sim 3$ A. However, as mentioned in the previous section, these values are based on the overestimated electric current strength.

We found the positive sense anomaly of $200 \sim 250 \mathrm{mV}$ amplitude around the summit area referring to the lowest SP at the southwestern flank $(-150 \mathrm{mV}$; Fig. 3). If we consider that the meteoric water downflow around the summit area is completely suppressed, the SP increase from -150 on the flank to $0 \mathrm{mV}$ might be caused only by the effect of suppressing meteoric water downflow. In that case, the electric current strength caused by the liquid-phase upflow would be reduced by a factor of 50/200 $\sim 100 / 250$ resulting the flow flux of $0.6 \sim 3 \times 10^{16} \kappa$ ton/day. If we take the $\mathrm{pH}$ dependence of zeta potential into account, further small value would be possible. Very acid hot springs $(\mathrm{pH}<2)$ are located at the foot of Iwodake, and they were formed by mixing of volcanic gases with local meteoric water near the surface (Shinohara et al., 1993). If pH of subsurface hydrothermal solution is also low, the zeta potential would be closer to zero.

If $\kappa=2 \times 10^{-13} \mathrm{~m}^{2}$, an upper limit of macroscopic permeability at $1 \mathrm{~km}$ depth (e.g., Manning and Ingebritsen, $1999)$, is used, the liquid-phase flux is calculated to be $1 \sim$ $6 \times 10^{3}$ ton/day that is one order smaller than $\mathrm{H}_{2} \mathrm{O}$ flux as the volcanic gases $\left(2.2 \times 10^{4}\right.$ ton/day; Hedenquist et al., 1994). If the permeability is $\sim 10^{-14}$ (which may be more realistic), contribution of the flux $J$ of meteoric water origin would be even smaller. That is consistent with the idea that the most part of the $\mathrm{H}_{2} \mathrm{O}$ discharging from the active vent is magmatic (Shinohara et al., 1993).

\section{Conclusions}

We conducted SP surveys twice on Satsuma-Iwojima. Almost the same profile was obtained by the two surveys over the Iwodake edifice, a lava dome of rhyolite. A SP anomaly of positive sense at altitudes higher than $300 \mathrm{~m}$ and the negative correlation with topography at the foot was detected along the traverse of the southwestern flank. The observed positive anomaly was explained by the combined model of linear topographic effect and a pair of the source and sink of conduction current beneath the summit crater. The model calculation well reproduced the observed SP features. The calculated depth of the source of conduction current is around the sea level and the sink is at several hundreds meters below it. A liquid-phase water upflow around an intruded magma and/or around a vapor-phase water upflow above a degassing magma was implied as a mechanism of carrying positive charges.

Observable area on the volcano edifice is often restricted as in the case of Iwodake. However, the present study revealed that the SP survey could be a powerful tool to outline the subsurface hydrothermal system, while quantitative interpretation is rather controversial. The difficulty of quantitative interpretation is caused by the facts that there are several mechanisms contribute the SP anomaly and that there are large uncertainties in parameters. In particular, some parameters such as resistivity or permeability of a host rock can vary several hundreds times in volcanic areas. Therefore, measurements of those parameters for each survey area are necessary to obtain more quantitative models.

Acknowledgments. We are grateful to Masato Iguchi, Kazuhiro Ishihara, and other staff of Sakurajima Volcano Research Center, Disaster Prevention Research Institute (DPRI), Kyoto University for their continuous supports and constructive discussions. Discussions with Yoshikazu Tanaka and Takeshi Hashimoto of Kyoto University were highly helpful. We would like to thank Nobuo Matsushima and other staffs of Geological Survey of Japan for their suggestions and cooperation to our observation. The valuable data could not be obtained without cooperation of people in Satsuma-Iwojima, Mishima village. Our thanks also go to the two reviewers (Tsuneo Ishido and an anonymous) and the editor in charge (Hiroshi Shinohara) for their constructive comments and suggestions. This study was supported by a grant in the 1999 fiscal year for "A comparison study on the shallow structure of volcanoes (K. Ishihara)" of DPRI, Kyoto University.

\section{References}

Corwin, R. F. and D. B. Hoover, The self-potential method in geothermal exploration, Geophysics, 44, 226-245, 1979.

Di Maio, R., P. Mauriello, D. Patella, Z. Petrillo, S. Piscitelli, and A. Siniscalchi, Electric and electromagnetic outline of the Mount SommaVesuvius structural setting, J. Volcanol. Geotherm. Res., 82, 219-238, 1998.

Geological Survey of Japan, Recent volcanic activity at the summit of Iwodake, Satsuma-Iwojima, in Report of Coordinating Committee for Prediction of Volcanic Eruption, 67, 79-82, 1997 (in Japanese).

Hashimoto, T., Y. Tanaka, T. Mogi, Y. Nishida, S. Ohba, K. Yamamoto, and K. Ishihara, Self-potential and hydrothermal system in the western part of Sakurajima Volcano, Annuals, Disas. Prev. Res. Inst., Kyoto Univ., 41 B-1, 145-151, 1998 (in Japanese with English abstract).

Hashimoto, T., Y. Tanaka, Y. Nishida, T. Mogi, K. Yamamoto, W. Kanda, J. Hirabayashi, and K. Ishihara, Self-potential and hydrothermal system in Sakurajima Volcano (2), Annuals, Disas. Prev. Res. Inst., Kyoto Univ., 42 B-1, 19-26, 1999 (in Japanese with English abstract).

Hedenquist, J. W., M. Aoki, and H. Shinohara, Flux of volatiles and oreforming metals from the magmatic-hydrothermal system of Satsuma Iwojima volcano, Geology, 22, 585-588, 1994.

Helgeson, H. C. and D. H. Kirkham, Theoretical prediction of the thermodynamic behavior of aqueous electrolytes at high pressures and temperatures: I. Summary of the thermodynamic/electrostatic properties of the solvent, Am. J. Sci., 274, 1089-1198, 1974.

Iguchi, M., K. Ishihara, T. Takayama, T. Tamekuri, H. Shinohara, and E. Saito, Volcanic activity at Satsuma-Iwojima during 1995-1998, Annuals, Disas. Prev. Res. Inst., Kyoto Univ., 42 B-1, 1-10, 1999 (in Japanese with English abstract).

Ishido, T., Self-potential generation by subsurface water flow through electrokinetic coupling, in Lecture notes in earth sciences, 27, Detection of subsurface flow phenomena, Springer-Verlag, Berlin, 121-131, 1989. 
Ishido, T., Subsurface fluid flow inferred from self-potential distribution in volcanic areas, in Proc. 1991 Conductivity Anomaly Symp., 86-93, 1991 (in Japanese).

Ishido, T. and H. Mizutani, Experimental and theoretical basis of electrokinetic phenomena in rock-water systems and its applications to geophysics, J. Geophys. Res., 86, 1763-1775, 1981.

Ishido, T., H. Mizutani, and K. Baba, Streaming potential observations, using geothermal wells and in situ electrokinetic coupling coefficients under high temperature, Tectonophys., 91, 89-104, 1983.

Ishido, T., T. Kikuchi, N. Matsushima, Y. Yano, S. Nakao, M. Sugihara, T. Tosha, S. Takakura, and Y. Ogawa, Repeated self-potential profiling of Izu-Oshima Volcano, Japan, J. Geomag. Geoelectr., 49, 1267-1278, 1997.

Kagiyama, T., H. Utada, and T. Yamamoto, Magma ascent beneath Unzen Volcano, SW Japan, deduced from the electrical resistivity structure, $J$. Volcanol. Geotherm. Res., 89, 35-42, 1999.

Kanda, W., T. Hashimoto, and H. Ohshima, Self-potential surveying of Suwanosejima Volcano, Annuals, Disas. Prev. Res. Inst., Kyoto Univ., 42 B-1, 11-18, 1999 (in Japanese with English abstract).

Kazahaya, K. and H. Shinohara, Excess degassing of active volcanoes: processes and mechanisms, Mem. Geol. Soc. Japan, 46, 91-104, 1996 (in Japanese with English abstract).

Manning, C. E. and S. E. Ingebritsen, Permeability of the continental crust: Implications of geothermal data and metamorphic systems, Rev. Geophys., 37, 127-150, 1999.

Michel, S. and J. Zlotnicki, Self-potential and magnetic surveying of La Fournaise volcano (Réunion Island): Correlations with faulting, fluid circulation, and eruption, J. Geophys. Res., 103, 17845-17857, 1998.

Nishida, Y. and H. Tomiya, Self-potential studies in volcanic areas (1) Usu Volcano-, J. Fac. Sci., Hokkaido Univ., Ser. VII (Geophysics), 8, 173-190, 1987.

Nourbehecht, B., Irreversible thermodynamic effects in inhomogeneous media and their applications in certain geoelectric problems, Ph.D. Thesis, M.I.T., 121 pp., 1963.

Ohminato, T. and D. Ereditato, Broadband seismic observations at
Satsuma-Iwojima volcano, Japan, Geophys. Res. Lett., 24, 2845-2848, 1997.

Ono, K., T. Soya, and T. Hosono, Geology of the Satsuma-Iō-jima District, Quadrangle Series, Scale 1:50,000, Geol. Surv. Japan, 80 pp., 1982 (in Japanese with English summary).

Patella, D., Self-potential global tomography including topographic effects, Geophy. Prosp., 45, 843-863, 1997.

Saito, G., K. Kazahaya, H. Shinohara, Y. Kawanabe, and J. Stimac, Degassing process of high temperature rhyolitic magma in the post-caldera stage of Satsuma-Iwojima volcano, Abst. Volcanol. Soc. Japan, 2, 146, 1996 (in Japanese).

Sasai, Y., J. Zlotnicki, Y. Nishida, P. Yvetot, P. Morat, H. Murakami, Y. Tanaka, Y. Ishikawa, S. Koyama, and W. Sekiguchi, Electromagnetic monitoring of Miyake-jima volcano, Izu-Bonin Arc, Japan: A preliminary report, J. Geomag. Geoelectr., 49, 1293-1316, 1997.

Shinohara, H., W. F. Giggenbach, K. Kazahaya, and J. W. Hedenquist, Geochemistry of volcanic gases and hot springs of Satsuma-Iwojima, Japan: Following Matsuo, Geochem. J., 27, 271-285, 1993.

Yasukawa, K. and T. Mogi, Topographic effects on SP anomaly caused by subsurface fluid flow-numerical approach-, Butsuri-Tansa (Geophys. Explor.), 51, 17-26, 1998 (in Japanese with English abstract).

Yoshida, M. and T. Ozawa, Amounts of some chemical components discharged from Satsuma-Iwo-Jima volcano in relation to their feeding sources, Bull. Volcanol. Soc. Japan, 26, 25-34, 1981.

Zablocki, C. J., Mapping thermal anomalies on an active volcano by the self-potential method, Kilauea, Hawaii, in Proc. 2nd U.N. Symp. on the Development and Use of Geothermal Resources, San Francisco, CA, U.S. Govt. Printing Office, Washington, D.C., 2, 1299-1309, 1976.

Zlotnicki, J., G. Boudon, J. P. Viodé, J. F. Delarue, A. Mille, and F. Bruère, Hydrothermal circulation beneath Mount Pelée inferred by self potential surveying. Structural and tectonic implications, J. Volcanol. Geotherm. Res., 84, 73-91, 1998.

W. Kanda (e-mail: kanda@ svo.dpri.kyoto-u.ac.jp) and S. Mori 